\title{
Association of Perception of Aging of Senior Citizen to Level of Awareness
}

\author{
Carlo Bryan C. Borrico ${ }^{1,2^{*}}$ and Esperanza Anita Arias ${ }^{1}$ \\ ${ }^{1}$ Department of Public Health, Angeles University Foundation, Angeles City, Philippines \\ ${ }^{2}$ Department of Public Health, Reyes Clinic and Hospital, Angeles City, Philippines \\ *Corresponding author: Carlo Bryan C Borrico, Department of Public Health, Angeles University Foundation, Angeles City, Philippines, E-mail: \\ borrico.carlo@auf.edu.ph \\ Received date: January 29, 2018; Accepted date: February 26, 2018; Published date: February 28, 2018 \\ Copyright: (c) 2018 Borrico CBC, et al. This is an open-access article distributed under the terms of the Creative Commons Attribution License, which permits \\ unrestricted use, distribution, and reproduction in any medium, provided the original author and source are credited.
}

\begin{abstract}
Background: This study aimed to determine the association of aging perception of senior citizen to level of awareness on their rights, benefits and privileges and living arrangements.

Methods: Four hundred (400) senior citizen residents in Barangay Dau were recruited and participated in the study. Frequency, percentage, mean, and standard deviation were used for descriptive while Mann-Whitney $U$ test and Kruskal-Wallis $\mathrm{H}$ test were used to determine which among socio-economic variables varies with aging perception. Spearman's rank-order correlation on the other hand was used to determine the relationship between the aging perception and their awareness on their rights, benefits and privileges.

Results: The result revealed that most participants have positive control over aging and think that aging have positive impact to their lives. They have less negative emotion toward aging and most of them accepted that they are growing old. Moreover, it was found out that among the socioeconomic factors identified, only gender and living arrangement had variation on aging perception. There is a positive correlation between senior citizen awareness of their rights, benefits and privileges and their belief that aging have positive impact on their life. In addition, there is an inverse relationship between age and Control-Negative indicating that as person grow older, they are more likely perceived that they have positive control over aging.
\end{abstract}

Keywords: Aging; Aging perception; Living arrangement; Senior citizens center act

\section{Introduction}

Aging is a progressive process that begins at birth. As people ages, changes in their bodies occur. They experience decline in heart function; change in joint structures; decrease in bone density; their skin becomes thinner, drier, and less elastic; and their vision starts to decline [1-4].

In addition, according to Horan et al. [5], senior citizens experience of health related changes can be attributed to old age and disease. Health related changes due to aging is the gradual and presently inevitable while health related changes attributed to disease was resulted from disease and poor health practices and are often preventable.

In fact, aside from these physiologic alterations, emotional and psychosocial changes may also occur. Individuals who are aging may experience loss of self-worth and identity [6-8], as well as life dissatisfaction $[9,10]$ due to several factors such as loss of spouse, decrease in income $[7,11]$, and poor health $[12,13]$. The lives of older persons may be influenced by their previous lifestyle, education, culture, perception, and beliefs and that there might be a decreased interaction between them and the society $[14,15]$.
Moreover, Barker et al. [16] developed the Aging Perceptions Questionnaire (APQ) to evaluate ones perception on aging. It comprises 32 likert scale items that represents seven aging perception domains: Timeline chronic (person accepted that they are growing old); Timeline cyclical (person experiences variation on aging); Consequences-positive (belief that aging has a positive impact on their lives); Consequences-negative (belief that aging has a negative impact on their lives); Positive control (perceived control over positive experiences of aging); Negative control (perceived control over negative experiences of aging); and Emotional representations (negative emotions generated by aging). In addition, Identity subscale examine the link between health related changes due to aging and health related changes attributed to disease; determining which among health related changes experienced by participants are either attributed to aging and disease (figure 1).

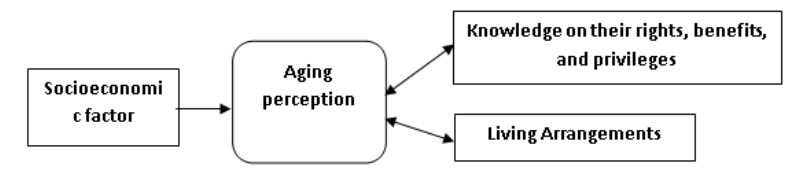

Figure 1: Conceptual Framework 
On the other hand, the Philippine government has embarked on enormous efforts to prosecute the policies of engaging and revitalizing the senior citizens while asserting the Filipino tradition of caring their elderly members. From the earliest law, Republic Act No. 7432 recognized the contributions of senior citizens in nation building. Under this law, it mandates the granting of the 20 percent discount from all establishments relative to utilization of transportation services, hotels, restaurants, and purchase of medicine anywhere in the country. Republic Act No. 9257 expanded the coverage of the benefits and privileges for senior citizens. Aside from provision of 20 percent discount, it proposed a comprehensive health care and rehabilitation system for disabled senior citizens. Republic Act No. 7876 mandates the establishment of a senior citizens' center in all cities and municipalities under the direct supervision of the DSWD in coordination with the Local Government Units.

However, in the report of Dr. De Leon, it was found that there is limited availability and accessibility of health services and medicines. Some elderly reported that some establishment do not give 20 percent discount especially on the purchase of medicines; being snubbed by the drivers and refuse to give them discount; limited health services in their community; and the travel time to reach the municipal hall to claim the senior ID (approximately $1 \mathrm{~h}$ ). Carlos added that poverty, senior citizen abuse, health status, and economic impact of aging as some issues that need to be addressed by the Philippine government. According to him, efforts to improve elderly health program and services could help reduce government health care spending.

According to Abejo [17], it is the duty of children to take care of their elder parents especially on physical, social, and financial support. The decision of the senior citizens to live alone is often determined by the economic resources available to them: senior citizens with fewer resources tend to co reside with their children compared to those with better resources. On the contrary, if the senior citizen are provided with some form of social security like old age pension, and health insurance or have some economic independence the children, particularly the unemployed, will be more likely to reside with them and take advantage of the available resources [18]. Abejo [17] added that the contemporary changes on society such as rise in labor force participation of women, increased migration and schooling have profound effects on families; making senior citizens seek alternative living arrangement such as living with relative or living in an institution.

\section{Conceptual framework}

Aging perception is defined as a personal evaluation of one's own aging. It is a process by which individuals develop perceptions about themselves as old persons. The living arrangement in this study was described in terms of the type of the household the senior citizen belongs to. It is whether the senior citizen owns a home, rents one, and lives with others. Burke et al. [19] conducted a study and found out that senior citizens who own their home and live with others have more positive control over their aging. Senior citizens who aged positively are more likely to engage in preventive health behavior Burke et al. [19]. They may seek understanding or knowledge on available government programs and services for senior citizens for them to become productive that would increase their self-worth and self-esteem.

In addition, knowledge on available senior citizens' programs and services may contribute to their perceived positive control over their aging and influence their belief that aging has a positive impact on them. Lastly, for sociodemographic aspect, Slotman et al. [20] found that those who were single, widowed, and low educated they are more likely to perceive that they have less control over aging and believe that aging has a negative impact on their life compared to those who were married, living with others and has higher educational attainment. Thus, this conceptual framework indicates that elderly knowledge on their rights, benefits, and privileges, living arrangement and socioeconomic factors influences persons perception on aging. This framework proposed that adapting in aging would be easier when senior citizens have the knowledge on their rights, benefits, and privileges.

Moreover, after a thorough search using ProQuest, EBSCOhost, Cumulative Index to Nursing and Allied Health Literature (CINAHL), Science Direct, and Gale Databases, it was found out that there is no published literature yet that correlates perception of aging to their level of awareness on their rights, benefits and privileges, and living arrangements. The study purports the idea of correlating the variables to contribute to additional knowledge for more innovative and realistic public health policy specifically on aging. Thus, this is the reason why the researcher decided to delve into this aspect as the focus of this paper.

\section{Methods}

\section{Participants}

The study was conducted in Barangay Dau upon the recommendation of the Head of Office for Senior Citizens Affair (OSCA). Proportionate Stratified Random sampling was used to select senior citizen participants randomly from 32 puroks. The inclusion criteria for selection were resident of any of these 32 puroks in barangay Dau who is at least 60 years of age, a Filipino citizen and able to decide if they want to participate in research or not; coherent; and the able to comprehend and communicate.

\section{Instrument of data collection}

The Aging Perceptions Questionnaire (APQ) by Barker et al. [16] was used in the study that assesses self-views on aging. Questions to capture knowledge on the different programs as well as living arrangements were added. The questionnaire was translated from English to Tagalog and vice versa. Moreover, pilot testing was conducted in Barangay Mawaque to check validity and reliability. A written informed consent was obtained from the participants in the pretesting.

\section{Procedure}

Participants were randomly selected using Stratified simple random sampling. An informed consent from the study participants after a detailed explanation of the nature of the study, potential risks and benefits that were associated with taking part in the study, as well as their right to refuse and/or withdraw any time during the course of the interview. A face to face interview with the aid of the cue cards was done. After completing the interview, the research assistants then checked the questionnaires for completeness and consistency.

\section{Statistical analysis}

Frequency, percentage, mean, and standard deviation were used for descriptive. Mann-Whitney U test and Kruskal-Wallis H test were used 
to determine association between socio-economic variables and aging perception. Spearman's rank-order correlation on the other hand was used to determine the relationship between aging perception and awareness and availment of their rights, benefits and privileges.

\section{Results and Discussion}

\section{Descriptive statistics}

Four hundred (400) senior citizens participated in the study. More than half of the participants were male (52\%), married $(74.5 \%)$ and retired. The mean age was $64+5$ years. Most participants reported pension (53.3\%), allowance from their children (51.5) and work (33.3\%) as their source of income. Most of them have financial contribution in household (84.8\%) and listed electric bill (76.1\%), food (71.1\%) and water bill $(66.7 \%)$ as their financial contribution in household. Additionally, most of them reported that they have senior citizen ID (98.8\%) and PHILHEALTH membership (83.8\%).

\section{Senior citizen living arrangement and their favor on institutionalization}

Participants were living with either their spouse $(72.5 \%)$ or children (63.7\%). With the exception of four (4) participants, majority of the participants were not in favor of institutionalization. With such a tightly knit family base, family support is very important. Senior citizens feel isolated and unworthy of living since they do not contribute or are unable to contribute towards the family's economy. Consequently, in the event that the children were unable to look and take care of their parents, they may coerce to admit their parents to home for the aged. Moreover, adapting western culture on living arrangement may significantly contribute to negative aging perception as the Philippines is accustomed to taking care of senior citizens in the family.

\section{Senior citizens' awareness and availment of their rights, benefits, and privileges}

Interestingly, all of the participants were aware of grant of twenty percent (20\%) discount from all establishments and provision of express lanes for senior citizens in all commercial and government establishments and reported they availed it. However, it is noticeable that all participants are not aware of the free medical and dental services in government establishments and the monthly stipend five hundred pesos (Php500.00) for indigent senior citizens.

\section{Senior citizens' perceptions on aging}

Most participants were more chronically aware in their aging process than perceiving variations in their aging process $(\bar{x}=3.90+0.41)$. This means that participants accepted they were growing old. On the other hand, all participants have positive control over their aging $(\bar{x}=3.83+0.49)$ and think that aging have positive impact to their lives across a variety of conditions $(\bar{x}=3.98+0.46)$. This implies that most participants believe that aging has positive impact to their lives.

When a person have positive views on aging, they have lesser mortality and they are more ready to cope on physical decline. A positive view on aging help boost a person's physiological function, sustain social interaction, maintain self-worth and enhance self- esteem. The more they think of the positive impacts, the higher their self-esteem will be Table 1 .

\begin{tabular}{|l|l|}
\hline APQ dimensions & Mean + SD \\
\hline Timeline-Chronic & $3.90+0.41$ \\
\hline Timeline-Cyclical & $3.67+0.44$ \\
\hline Emotionality representation & $3.49+0.55$ \\
\hline Control-Positive & $3.83+0.49$ \\
\hline Control-Negative & $3.14+0.77$ \\
\hline Consequence- Positive & $3.98+0.46$ \\
\hline Consequence- Negative & $2.96+0.70$ \\
\hline
\end{tabular}

Table 1: Senior citizen perceptions on aging living on barangay Dau

It was also observed that all participants have low score on emotional representation $(\bar{x}=3.49+0.55)$. These emotional representations were negative emotions generated by aging included worry, anxiety, depression, distress, irritation, sadness, and the like Barker et al. [16]. This means that participants have less negative emotion which is reflected the participant's high score on control positive and consequence positive.

\section{Senior citizens' perceptions on aging and socioeconomic factors}

It was found out that among the socioeconomic factors, only gender and living arrangement had variation on aging perception. Table 2 showed that mean scores showed that males were more likely to perceive that aging have positive impact to their lives across a variety of conditions than females $(\bar{x}=4.02)$.

\begin{tabular}{|l|l|l|l|}
\hline APQ dimensions & $\begin{array}{l}\text { Male } \\
(\mathbf{n = 2 0 8})\end{array}$ & $\begin{array}{l}\text { Female } \\
(\mathbf{n = 1 9 2})\end{array}$ & -value $^{\mathrm{M}}$ \\
\hline Timeline-Chronic & 3.93 & 3.87 & 0.103 \\
\hline Timeline-Cyclical & 3.68 & 3.67 & 0.516 \\
\hline Control-Positive & 3.83 & 3.83 & 0.714 \\
\hline Control-Negative & 3.12 & 3.15 & 0.677 \\
\hline Consequence- Positive & 4.02 & 3.94 & 0.045 \\
\hline Consequence- Negative & 2.99 & 2.91 & 0.086 \\
\hline Emotionality representation & 2.9 & 3.03 & 0.007 \\
\hline
\end{tabular}

Table 2: Comparison of Mean APQ Score by gender; M- MannWhitney U

This is further supported by higher mean score of female on emotional representation $(\overline{\mathrm{x}}=3.03)$ stating that female were more likely to response to aging negatively (e.g. I get depress when I think about getting older). This also implies that males were more likely to perceive that aging have positive impact to their lives.

On the other hand, Table 3 showed that senior citizens who area living alone were more likely to believe that they have negative control over experience in aging $(\overline{\mathrm{x}}=3.43)$. This implies those senior citizens 
who live alone hold the least positive perceptions of aging. They believe that they have negative control over their aging such as mobility and social life (e.g. Getting older restricts the things that I can do.).

\begin{tabular}{|l|l|l|l|}
\hline APQ dimensions & $\begin{array}{l}\text { Living alone } \\
(\mathbf{n = 2 6 )}\end{array}$ & $\begin{array}{l}\text { Living with others } \\
(\mathbf{n}=\mathbf{3 7 4})\end{array}$ & $\begin{array}{l}\text { p- } \\
\text { value }^{\mathrm{M}}\end{array}$ \\
\hline Timeline-Chronic & 3.82 & 3.91 & 0.133 \\
\hline Timeline-Cyclical & 3.53 & 3.68 & 0.063 \\
\hline Control-Positive & 3.7 & 3.84 & 0.127 \\
\hline Control-Negative & 3.43 & 3.11 & 0.031 \\
\hline $\begin{array}{l}\text { Consequence- } \\
\text { Positive }\end{array}$ & 3.9 & 3.99 & 0.058 \\
\hline $\begin{array}{l}\text { Consequence- } \\
\text { Negative }\end{array}$ & 2.77 & 2.97 & 0.381 \\
\hline $\begin{array}{l}\text { Emotionality } \\
\text { representation }\end{array}$ & 3.42 & 3.49 & 0.369 \\
\hline
\end{tabular}

Table 3: Comparison of Mean APQ Score by Living arrangement; MMann-Whitney U

\section{Senior citizens' perceptions on aging and their awareness and availment of their rights, benefits and privileges}

The relationship between the senior citizen's perception of aging to their awareness and availment of their benefits and privileges was reported in Table 4. There was a positive correlation between Consequence- Positive and awareness of their privileges and benefits ( $\mathrm{r} .110, \mathrm{p}<0.05)$. On the other hand, there was an inverse significant correlation between age and Control-Negative to awareness of the benefits and privileges $(\mathrm{r}-.109-.124, \mathrm{p}<0.05)$. This implies that as ones believe that they able to control the positive effect of aging and perceive that aging have positive impact to their lives, they were more likely to be aware of their right, benefits and privileges. This also implies that growing older has no relation to awareness of their right, benefits and privileges.

\begin{tabular}{|c|c|c|}
\hline \multicolumn{2}{|l|}{ Awareness } & \multirow{2}{*}{$\begin{array}{l}\text { Availment } \\
0.137\end{array}$} \\
\hline Aware & & \\
\hline Age & $-0.124^{*}$ & 0.131 \\
\hline Educational attainment & -0.057 & $0.124^{*}$ \\
\hline Timeline-Chronic & -0.093 & 0.016 \\
\hline Timeline-Cyclical & -0.025 & 0.133 \\
\hline Control-Positive & 0.151 & 0.055 \\
\hline Control-Negative & $-.109^{*}$ & -0.072 \\
\hline Consequence- Positive & $0.110^{*}$ & 0.058 \\
\hline Consequence- Negative & 0.064 & $0.109^{*}$ \\
\hline Emotionality representation & 0.054 & 0.071 \\
\hline
\end{tabular}

Table 4: Association between the senior citizen perception of aging to their awareness and availment of their privileges and benefits; Correlation is significant at the 0.05 level (2-tailed).
Consequently, there was a significant positive correlation between Educational attainment and Consequence- Negative to senior citizen avail of their rights, benefits and privileges $(\mathrm{r} .109-.124, \mathrm{p}<0.05)$. This implies that senior citizens with higher educational attainment and perceived that aging have negative impact to their lives were more likely to avail their right, benefits and privileges.

\section{Participants' identity on aging}

Figure 2 showed the result of senior citizen's identity on aging (refer to the beliefs that there is a link between aging and health-related changes). Most participants reported experiencing painful joints (78.5\%), slowing down (69.3\%), not being mobile (68.5\%), loss of balance (67.5\%), loss of strength $(66.0 \%)$ and cramps (63.0\%). Most of them think that not being mobile (65.5\%), loss of balance (64.8\%), loss of strength $(61.5 \%)$ and slowing down $(61.0 \%)$ as one of the most common age- related changes that may occur.

Identifying the discrepancy between the health-related changes and those attribute to aging is important for health sector and administrator to identify which health related changes can be attributed to old age and disease. Health related changes is slow, progressive and inevitable while aging result from illness and poor lifestyle (e.g. no physical activity, active smoker, eating fatty and salty foods) are often manageable and preventable.

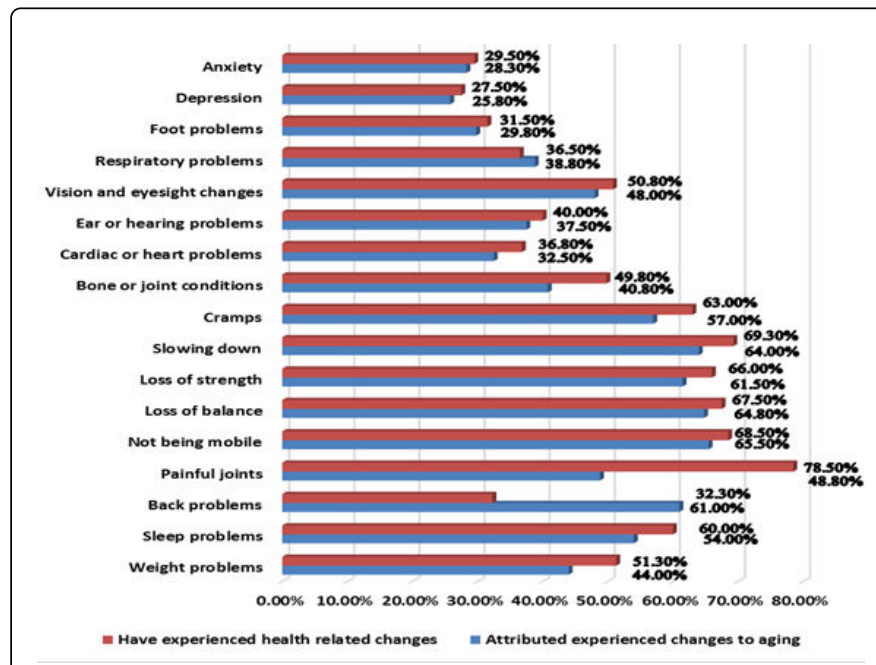

Figure 2: Participants' identity on aging.

The data showed that there was a greater proportion of those who experience the symptoms but do not attribute it to the aging process. This may be because some of the participants might have been feeling the symptoms before they have reached the age of 60 . Further, they attributed the health related changes to disease conditions they were diagnosed of (arthritis, hypertension) and poor health practices rather than the result of changes that occur with the aging process. This result should warrant attention especially to health care worker and health administrator.

\section{Limitations and further research}

Limitations may include that since the study was done in only one area, it did not cover the peculiarities across urban and rural areas, as well as regional and cultural diversities. Additionally, the study was 
unable to measure the awareness and avail of senior citizen's rights on Philippines. Future study may also look forward of including per capital income per household including household member's monthly contributions and financial contribution. Considering these variables would help to determine the socio-economic status of senior citizen.

Consequently, senior citizen quality of life variable may also need to consider as quality of life in senior citizen can be affected by many socio economic and environmental factors. Correlating senior citizen quality of life to aging perception could strengthen the result and help well understand senior citizen. Future studies are also needed for assessing other influential factors on the quality of life in senior citizen. Moreover, the result in this study could not generalize to senior citizen in other regions or nationwide as this study was only confined to barangay Dau. The researcher suggests conducting the same study on other regions to more represent the cultural diversity of Filipinos.

\section{Conclusion}

This study aimed to determine the association of perception of aging of senior citizen to level of awareness on their rights, benefits and privileges and living arrangements. Based on the above analyses the following policy recommendations related to study can be considered: The government must create more programs focusing on giving senior citizen longer and better lives by creating and implementing alternative occupational programs to maintain their sense of self-worth and selfesteem. Emphasis should also be put on disease prevention, health promotion, and wellness of mind, body and spirit.

\section{Conflict of interest}

The authors have no conflicts of interest to disclose

\section{Acknowledgements}

This thesis would not have been made possible without the guidance and the help of several individuals who in one way or another contributed and extended their valuable assistance in the preparation and completion of this study. The researcher wishes to convey his profound gratitude to the following significant persons: Dr. Carmela S. Dizon, dean of the AUF Graduate School for instilling to the graduate students the value of diligence and excellence. Reynaldo DL. Bundalian Jr., Assistant Director of AUF's Center for Research and Development, for his guidance and support to improve the study. Madonna Valenzuela, Statistician, for her analysis and interpretation of the findings of the study. Dr. Bella G. Panlilio, Ethics Review committee head for her kind concern and consideration regarding the researcher's academic and ethical requirements. Dr. Esperanza Arias, for her unselfish and unfailing support as the Thesis adviser, for giving constructive criticisms and insightful suggestions. Dr. Oscar Aurelio, Barangay Captain of Dau, for accommodating the researcher in his place to conduct the study. Panelists: Dr. Josephine D. Agapito, Dr. Razel L. Kawano, and Dr. Olga Angelinetta P. Tulabut, for their valuable feedback and insightful comments. To the researcher's family, for their support and advice especially his mother for helping him believe that he could get through this work.

\section{References}

1. Farage M, Miller K, Berardesca E, Maihadt H (2009) Clinical Implications of Aging Skin: Cutaneous Disorders in the Elderly. Am J Clin Dermatol 10: 73-86.

2. Mauk K (2010) Gerontological Nursing competencies for care. Jones and Barlett publishers.

3. Miller C (2009) Nursing for wellness in older adults. Wolter's kluwer/ Lippincott William and wilkins.

4. Touchy T, Jett K (2010) Gerontological Nursing Healthy Aging. Mosby Elsevier.

5. Pendleton N, Horan MA (1995) The relationship between aging and disease. Rev Clin Gerontol 5: 125-141.

6. Bigby C, Wilson N, Balandin S, Stancliffe R (2011) Disconnected expectations: Staff, family, and supported employee perspectives about retirement. J Intellect Dev Disabil 36: 167-174.

7. Robinson O, Demetre J, Corney R (2011) The variable experiences of becoming retired and seeking retirement guidance: a qualitative thematic analysis. Br J Guid Counc 39: 239-258.

8. Silva MG, Boemer MR (2009) The experience of aging: a phenomenological perspective. Rev Lat Am Enfermagem 17: 380-386.

9. Kleinspehn-Ammerlahn A, Kotter-Gruhn D, Smith J (2008) Selfperceptions of aging: o subjective age and satisfaction with aging change during old age? J Gerontol B Psychol Sci Soc Sci 63: 377.

10. Scherger S, Nazroo J, Higgs P (2010) Leisure activities and retirement: do structures of inequality change in old age? Ageing Society 31: 146-172.

11. Hewitt A, Howie L, Feldman S (2010) Retirement: what will you do? A narrative inquiry of occupation-based planning for retirement: implications for practice. Aust Occup Ther J 57: 8-16.

12. Li I, Chen Y, Kuo H (2005) The health status and health promotion behavior of low-income elderly in the Taipei area. J Nurs Res 13: 305-312.

13. Sumngern C, Azeredo Z, Subgranon R, Sungvorawongphana N, Matos E (2010) Happiness among the elderly in communities: A study in senior clubs of Chonburi Province, Thailand. Jpn J Nurs Sci 7: 47-54.

14. Cumming E, Henry WE (1961) Growing old: The process of disengagement. New York: Norton.

15. Eliopoulos C (2001) Gerontological Nursing. Philadelphia. Lippincott.

16. Barker M, O'Hanlon A, McGee H, Hickey A, Conroy R (2007) Crosssectional validation of the Aging Perceptions Questionnaire: a multidimensional instrument for assessing self-perceptions of aging. BMC Geriatr 7: 9.

17. Abejo S (2004) Living Arrangements of the Elderly in the Philippines. National Statistics Office.

18. Panigrahi AK (2009) Determinants of Living Arrangements of Elderly in Orissa: An Analysis. The Institute for Social and Economic Change, Bangalore.

19. Burke H, Cronin H, Hickey A, McGee H, Morgan K, et al. (2011) Quality Of Life and Beliefs about Ageing. In Fifty plus in Ireland 2011: First results from The Irish Longitudinal Study on Ageing (TILDA).

20. Slotman A, Cramm J, Nieboer A (2015) Validation of the Dutch Aging Perceptions Questionnaire and development of a short version. Health Qual Life Outcomes 13: 54. 